\title{
Caracterização pós-colheita de milho doce submetido ao parcelamento de fertirrigação nitrogenada
}

\author{
Post-harvest characterization of sweet corn submitted to nitrogen fertigation
}

\author{
Danielle Godinho de Araújo Perfeito ${ }^{1 *}$, Milene Cristina Mendes Lopes ${ }^{1}$, Leandro Caixeta Salomão², \\ Mara Lúcia Cruz de Souza ${ }^{2}$, Cleiton Gredson Sabin Benett ${ }^{2}$, Bárbara Paiva de Lima ${ }^{1}$ \\ 1 Instituto Federal Goiano (IF Goiano), Departamento de Tecnologia em Alimentos, Urutaí/GO - Brasil \\ 2 Instituto Federal Goiano (IF Goiano), Departamento de Engenharia Agrícola, Urutaí/GO - Brasil
}

\section{${ }^{*}$ Corresponding Author}

Danielle Godinho de Araújo Perfeito, Instituto Federal Goiano (IF Goiano), Departamento de Tecnologia em Alimentos, Campus Urutaí, Rodovia Geraldo Silva Nascimento, km 2,5, CEP: 75790-000, Urutaí/GO - Brasil, danielle.araujo@ifgoiano.edu.br

Cite as: Post-harvest characterization of sweet corn submitted to nitrogen fertigation. Braz. J. Food Technol., v. 20, e2016140, 2017.

Received: Oct. 4, 2016; Approved: June 27, 2017

\section{Resumo}

A presente pesquisa teve como objetivo avaliar a qualidade pós-colheita do milho doce submetido ao processo de parcelamento do nutriente nitrogênio, aplicado via fertirrigação, através de parâmetros físicos, químicos e sensoriais. A cultivar de milho doce utilizada foi a Doce Cristal (BR-402), sob a influência da fertirrigação em quatro tratamentos, com diferentes parcelamentos de nitrato de amônio, sendo Tratamento 1:2 aplicações; Tratamento 2: 4 aplicações; Tratamento 3: 6 aplicações, e Tratamento 4: 8 aplicações. As espigas foram avaliadas quanto aos parâmetros físicos de comprimento, diâmetro e massa; físico-químicos de pH, sólidos solúveis, umidade e cinzas; análise sensorial, através do teste de aceitação, além da avaliação instrumental da textura. Nos parâmetros físicos, os tratamentos influenciaram apenas na característica diâmetro das espigas com palha $(5,3 \mathrm{~cm}$ a $5,8 \mathrm{~cm})$ e sem palha $(4,3 \mathrm{~cm}$ a 4,7 cm). Nas análises físico-químicas, apenas a acidez titulável em ácido málico não apresentou diferença entre os tratamentos, sendo que os sólidos solúveis apresentaram maior diferença entre os tratamentos, com o Tratamento 4 apresentando $15^{\circ}$ Brix e o Tratamento $2,17^{\circ} \mathrm{Brix}$. Os tratamentos não influenciaram na aceitação sensorial das espigas de milho doce, as quais apresentaram boa aceitação sensorial para todos os atributos avaliados, com médias hedônicas superiores a 7,3.

Palavras-chave: Zea mays L.; Análise sensorial; Adubação nitrogenada.

\section{Abstract}

The aim of this research was evaluate the quality of sweet corn submitted to the nitrogen nutrient installment process applied by fertigation from the physical, chemical and sensory parameters. The cultivar of sweet corn used in the experiment was Doce Cristal (BR-402), submitted to the influence of fertigation in 4 treatments with different installments of ammonium nitrate: Treatment 1:2 applications, Treatment 2: 4 applications, Treatment 3: 6 applications and Treatment 4: 8 applications. The corn cobs were evaluated for the physical parameters of length, diameter and mass; the physicochemical parameters of $\mathrm{pH}$, soluble solids, moisture and ash; and a sensory analysis using the acceptance test as well as the instrumental texture analysis. For the physical parameters, the treatments only affected the diameter of the ears with $(5.3 \mathrm{~cm}$ to $5.8 \mathrm{~cm})$ and without $(4.3 \mathrm{~cm}$ to $4.7 \mathrm{~cm}$ ) the straw. In the physicochemical analysis only titratable acidity measured as malic acid did not differ between treatments, and the soluble solids showed the greatest difference between treatments with treatment 4 presenting $15^{\circ} \mathrm{Brix}$ and treatment $217^{\circ} \mathrm{Brix}$. The treatments did not influence the sensory acceptance of the sweet corn cobs, which showed good acceptability for all attributes evaluated, with average hedonic scores greater than 7.3.

Keywords: Zea mays L.; Sensory analysis; Nitrogen fertilization. 


\section{Introdução}

A fertirrigação é uma prática de adubação em que os nutrientes são aplicados nos cultivos de forma parcelada, juntamente com a água de irrigação (TRANI et al., 2011). Essa técnica promove o uso racional de fertilizantes em agricultura irrigada, uma vez que aumenta a eficiência de uso do fertilizante, disponibiliza nutrientes no volume de solo explorado pelo sistema radicular da cultura e reduz a mão de obra e o custo com máquinas (SOUZA et al., 2011).

O principal destino do milho doce é o processamento pelas indústrias de vegetais em conserva (OLIVEIRA JUNIOR et al., 2006). Devido a uma mutação espontânea do milho convencional (BHATT et al., 2012), a presença de alelos que bloqueiam a conversão de açúcares em amido no endosperma confere aos grãos alto teor de açúcares e baixo teor de amido (ZUCARELI et al., 2012), caracterizando uma matéria-prima com excelentes características sensoriais para a indústria de conservas.

Estudos no Brasil sobre as características físicas, químicas e sensoriais do milho doce são escassos e grande parte das informações encontradas está relacionada apenas a variáveis produtivas. De acordo com Cruz (2014), a elevada produtividade desejada nem sempre coincide com espigas comerciais adequadas ao processamento para obtenção de alto rendimento industrial.

Assim como as condições climáticas, o manejo de adubação e outros fatores limitantes ao desenvolvimento da planta, e a manutenção do seu estado fisiológico pós-colheita podem refletir em alterações na sua qualidade, impactando o processamento industrial. Xiaolong e Yunfei (2011) observaram a manutenção de menor taxa de respiração e menor perda de açúcar em milho doce fresco armazenado a $-1{ }^{\circ} \mathrm{C}$ (ponto de congelamento), quando comparado ao mesmo milho armazenado resfriado a $4{ }^{\circ} \mathrm{C}$.

Diante da importância da caracterização tecnológica de qualquer matéria-prima para o sucesso do processamento industrial, este estudo teve como objetivos a caracterização e a comparação de atributos físicos, químicos e sensoriais de milho doce submetido a diferentes manejos de fertirrigação.

\section{Material e métodos}

\subsection{Cultivar e condução do experimento}

O milho foi produzido em ambiente protegido na área experimental da Unidade Educacional de Produção (UEP) de Olericultura do Instituto Federal Goiano, Campus Urutaí, em Urutaí-GO, cujas coordenadas geográficas são $17^{\circ} 29^{\prime} 10^{\prime \prime} \mathrm{S}$ de latitude, 48²'38" O de longitude e $697 \mathrm{~m}$ de altitude.

A cultivar de milho doce utilizada no experimento foi a Doce Cristal (BR-402), a qual é mais rústica e, portanto, mais indicada para hortas domésticas. O manejo da irrigação foi realizado através de um tanque evaporímetro com altura de $24 \mathrm{~cm}$ e $52 \mathrm{~cm}$ de diâmetro, instalado no centro do ambiente protegido, seguindo a metodologia descrita por Salomão (2012).

O turno de rega adotado foi de dois dias. Não houve diferenciação das lâminas de água aplicadas entre os tratamentos, apenas da quantidade de fertilizante referente ao diferente parcelamento da adubação aplicado em cada tratamento.

A adubação total recomendada foi parcelada e dividida em função da quantidade de parcelamento do nutriente nitrogênio (N) (Tratamentos), sendo definida com base na análise de solo e então aplicada na forma de nitrato de amônio ( $33 \%$ de N), seguindo as recomendações de Trani et al. (2011).

Os tratamentos foram constituídos de quatro níveis de parcelamento de nitrogênio ao longo do ciclo da cultura, sendo: Tratamento 1 (T1): 2 aplicações; Tratamento 2 (T2): 4 aplicações; Tratamento 3 (T3): 6 aplicações e Tratamento 4 (T4): 8 aplicações, ao longo do experimento (Tabela 1).

O delineamento estatístico empregado foi de blocos casualizados com quatro tratamentos e cinco repetições, totalizando 20 parcelas experimentais, representadas por canteiros de dimensões de $2 \mathrm{~m}$ de comprimento por $1 \mathrm{~m}$ de largura.

\subsection{Colheita e parâmetros físicos}

A colheita foi realizada manualmente, assim como o descascamento. Seis espigas de cada repetição, com e sem palha, foram avaliadas quanto ao diâmetro central e ao comprimento através de paquímetro digital. Também foi

Tabela 1. Cronograma de aplicação de nitrato de amônio.

\begin{tabular}{|c|c|c|c|c|c|c|c|c|c|}
\hline \multirow{3}{*}{ Tratamento } & \multicolumn{8}{|c|}{ Parcelamento } & \multirow{2}{*}{ Total } \\
\hline & 15 & 21 & 25 & 31 & 35 & 41 & 45 & 51 & \\
\hline & \multicolumn{8}{|c|}{ Dias após a emergência } & kg de NH \\
\hline $\mathrm{T} 1$ & 1,8 & & & & & 1,8 & & & 3,60 \\
\hline T2 & 0,9 & & 0,9 & & 0,9 & & 0,9 & & 3,60 \\
\hline T3 & 0,6 & 0,6 & 0,6 & 0,6 & 0,6 & 0,6 & & & 3,60 \\
\hline T4 & 0,45 & 0,45 & 0,45 & 0,45 & 0,45 & 0,45 & 0,45 & 0,45 & 3,60 \\
\hline
\end{tabular}


determinada a massa de cada espiga com e sem palha, em balança semianalítica.

\subsection{Análise sensorial}

Imediatamente após a colheita e a avaliação dos parâmetros físicos, as espigas foram lavadas em água corrente e posteriormente sanitizadas em solução com hipoclorito de sódio $100 \mathrm{mg} \mathrm{L}^{-1}$, durante 15 minutos. Após a sanitização, as espigas foram imersas, durante três minutos, em solução de hipoclorito de sódio a $5 \mathrm{mg} \mathrm{L}^{-1}$, para enxágue. As espigas foram cortadas em três partes iguais, sendo retiradas as pontas, com posterior cozimento em água mineral, por 25 minutos.

A análise sensorial do milho doce foi realizada por 40 indivíduos saudáveis, não fumantes, com faixa etária entre 18 anos a 60 anos de idade, sendo estudantes, funcionários e frequentadores do Instituto Federal Goiano - Campus Urutaí, com o hábito de consumir o produto avaliado (CAAE: 52342015.0.0000.0036).

Foi aplicado o teste de aceitação com escala hedônica estruturada de nove pontos, abrangendo de "desgostei muitíssimo" (1) a "gostei muitíssimo" (9). Os 40 consumidores de milho degustaram, de forma monádica sequencial, as espigas correspondentes aos quatro tratamentos. Foram avaliados os atributos: aparência, sabor e textura. A intenção de compra do produto foi testada, na mesma ficha, em uma escala de cinco pontos, de certamente não compraria (1) a certamente compraria (5). Na medida em que podia ocorrer algum tipo de alteração no conteúdo de açúcar do milho doce, em função dos diferentes tipos de tratamento, o teste do ideal foi empregado para o atributo gosto doce, utilizando uma escala de nove pontos (MEILGAARD et al., 1999), variando de "extremamente menos doce que o ideal" a "extremamente mais doce que o ideal".

As amostras de milho foram servidas na temperatura ambiente $\left(25^{\circ} \mathrm{C}\right)$, em pratos descartáveis, codificados com números aleatórios de três dígitos, de forma casualizada, em blocos completos balanceados, em cabines individuais com iluminação, utilizando-se luz branca. Juntamente com a amostra, os consumidores receberam a ficha de análise e um copo com água para lavar a boca entre as amostras.

\subsection{Textura instrumental}

As determinações dos parâmetros de textura instrumental das amostras foram realizadas na manhã seguinte à colheita do milho, em texturômetro TA-XT2 Plus (Stable Micro Systems, Surrey, Inglaterra), com análise de compressão por força normal, e os atributos de punção, penetração, extrusão, ruptura e relaxação de tensão nos grãos foram medidos de forma individual. Foram empregados os seguintes parâmetros: deformação (porcentagem de deformação em relação à altura inicial) de $80 \%$; altura média das amostras (return distance - calibração) $0,45(0,6)$; temperatura de $25^{\circ} \mathrm{C}$; geometria recomendada P 36 R, sem lubrificação; velocidade de compressão de $2 \mathrm{~mm} / \mathrm{s}$, e com resultado esperado de máxima resistência à pressão. $O$ perfil de textura foi acompanhado nos quatro tratamentos com 12 repetições.

\subsection{Análise físico-química e tratamento estatístico}

As análises físico-químicas foram realizadas acerca dos seguintes parâmetros: determinação do pH utilizando potenciômetro, Digimed ${ }^{\circledR}$ DM-20, calibrado com solução tampão pH 4 e 7; acidez titulável, por titulação em $\mathrm{NaOH} 0,1 \mathrm{M}$, sendo os resultados expressos em porcentagem de ácido málico; sólidos solúveis, determinados com base na leitura direta dos graus Brix da amostra a $20^{\circ} \mathrm{C}$, em refratômetro digital da marca LEICA, mod. AR200; umidade, dados obtidos por secagem em estufa Tecnal TE394/1, com circulação e renovação de ar, a $85^{\circ} \mathrm{C}$; cinzas, por incineração em mufla para calcinação à temperatura de $550{ }^{\circ} \mathrm{C}$. Todas as análises foram realizadas conforme metodologias para análise de alimentos do Instituto Adolfo Lutz (IAL, 2008).

Os resultados obtidos no teste de aceitação foram analisados por ANOVA/teste Tukey a 5\% de probabilidade, utilizando-se o software Sensomaker. Para o teste do ideal e o teste de intenção de compra, foi realizada análise de frequência das respostas dadas pelos consumidores.

As análises físico-químicas de $\mathrm{pH}$, acidez total titulável em ácido málico, sólidos totais, sólidos solúveis, cinzas (realizadas em triplicata) e de textura instrumental tiveram seus dados analisados por ANOVA/teste Tukey a $5 \%$ de probabilidade.

\section{Resultados e discussões}

\subsection{Características físicas}

No que diz respeito às características físicas das espigas de milho analisadas (Tabela 2), apenas a característica diâmetro das espigas com palhas e sem palhas apresentou diferença estatística entre os tratamentos; para os demais atributos estudados, não houve diferença estatística.

Os valores de comprimento e massa das espigas sem palhas (Tabela 2) foram todos superiores aos encontrados por PAES et al. (2010) para cinco cruzamentos de linhagens de milho doce da cultivar ViVi, em sistema de adubação tradicional, em que o maior comprimento foi de $18,41 \mathrm{~cm}$ e a maior massa, de 191,47 g.

Na indústria, para uma maior eficiência das máquinas degranadoras e maior rendimento industrial, o comprimento das espigas deve ser superior a $15 \mathrm{~cm}$ e o diâmetro maior que 3,0 cm (BARBIERI et al., 2005). Em relação a ambos os parâmetros, todos os tratamentos de fertirrigação com nitrato de amônio atenderam ao requisito da indústria de 
Caracterização pós-colheita de milho doce submetido ao parcelamento de fertirrigação nitrogenada

Perfeito, D. G. A. et al.

Tabela 2. Caracterização física das espigas dos diferentes tratamentos de fertirrigação em milho doce.

\begin{tabular}{lrrrr}
\multicolumn{1}{c}{ Parâmetros } & T1 & T2 & T3 & T4 \\
Comprimento das espigas com palha $(\mathrm{cm})$ & $30,86^{\mathrm{a}}$ & $29,83^{\mathrm{a}}$ & $30,23^{\mathrm{a}}$ & $29,93^{\mathrm{a}}$ \\
Comprimento das espigas sem palha (cm) & $19,78^{\mathrm{a}}$ & $20,95^{\mathrm{a}}$ & $20,56^{\mathrm{a}}$ & $20,95^{\mathrm{a}}$ \\
Diâmetro das espigas com palha (cm) & $5,34^{\mathrm{b}}$ & $5,37^{\mathrm{b}}$ & $5,81^{\mathrm{a}}$ & $5,67^{\mathrm{ab}}$ \\
Diâmetro das espigas sem palha (cm) & $4,70^{\mathrm{a}}$ & $4,35^{\mathrm{b}}$ & $4,64^{\mathrm{ab}}$ & $4,49^{\mathrm{ab}}$ \\
Massa das espigas com palha (g) & $347,83^{\mathrm{a}}$ & $342,00^{\mathrm{a}}$ & $343,89^{\mathrm{a}}$ & $327,33^{\mathrm{a}}$ \\
Massa das espigas sem palha $(\mathrm{g})$ & $233,50^{\mathrm{a}}$ & $242,33^{\mathrm{a}}$ & $237,30^{\mathrm{a}}$ & $218,33^{\mathrm{a}}$ \\
\hline
\end{tabular}

Médias seguidas de letras iguais na mesma linha não diferem significativamente pelo teste de Tukey $(p>0,05)$. T1: 2 aplicações; T2: 4 aplicações; T3: 6 aplicações e T4: 8 aplicações, ao longo do experimento de nitrato de amônio.

Tabela 3. Parâmetros físico-químicos de milho doce submetido a diferentes tratamentos de fertirrigação.

\begin{tabular}{lcccc}
\multicolumn{1}{c}{ Parâmetros } & T1 & T2 & T3 & T4 \\
$\mathrm{pH}$ & $6,9^{\mathrm{b}}$ & $6,88^{\mathrm{b}}$ & $7,11^{\mathrm{a}}$ & $7,10^{\mathrm{a}}$ \\
Acidez (\% ácido málico) & $1,46^{\mathrm{a}}$ & $1,36^{\mathrm{a}}$ & $1,19^{\mathrm{a}}$ & $1,11^{\mathrm{a}}$ \\
Sólidos Solúveis $\left({ }^{\circ} \mathrm{Brix}\right)$ & $16,00^{\mathrm{b}}$ & $17,00^{\mathrm{a}}$ & $16,00^{\mathrm{b}}$ & $15,00^{\mathrm{c}}$ \\
Umidade $\left(\mathrm{g} 100^{-1} \mathrm{~g}\right)$ & $72,79^{\mathrm{a}}$ & $69,08^{\mathrm{b}}$ & $73,20^{\mathrm{a}}$ & $73,61^{\mathrm{a}}$ \\
Cinzas $\left(\mathrm{g} 100^{-1} \mathrm{~g}\right)$ & $1,93^{\mathrm{b}}$ & $2,01^{\mathrm{a}}$ & $1,92^{\mathrm{b}}$ & $1,89^{\mathrm{b}}$ \\
\hline
\end{tabular}

Médias seguidas de letras iguais na mesma linha não diferem significativamente pelo teste de Tukey ( $p>0,05)$. T1: 2 aplicações; T2: 4 aplicações; T3: 6 aplicações e T4: 8 aplicações, ao longo do experimento de nitrato de amônio.

comprimento e diâmetro das espigas, com valores bem superiores ao mínimo exigido.

Assim como neste estudo, Cruz (2014) observou que as doses e os modos de parcelamento de $\mathrm{N}$ não influenciaram o comprimento de espigas de milho superdoce GSS 41240, que apresentou média de 19,3 cm de comprimento.

Observando-se os valores encontrados nos tratamentos do milho doce por fertirrigação para a massa das espigas com palha e sem palha, verificou-se que as espigas submetidas ao processo de fertirrigação apresentaram maior massa média que a verificada na pesquisa com milho doce cv. Doce Cristal, sem processo de fertirrigação, de Freitas et al. (1998), na qual foram encontrados os valores médios de 288,71 g e 197,66 g para o peso das espigas com palha e sem palha, respectivamente.

A maior massa das espigas gera benefícios tanto para o produtor quanto para a indústria, visto que a maior rentabilidade para o agricultor possibilita produzir mais em menor área; assim, a indústria pode comprar matéria-prima com menor custo, devido aos menores gastos com logística e colheita (BARBIERI et al., 2005).

Mendonça et al. (1999), estudando o efeito do nitrogênio na cultura do milho através da fertirrigação, observaram que o aumento de doses de nitrogênio causou aumento do peso dos grãos e do comprimento de espigas, em concordância com este trabalho, quando comparados aos obtidos por processos de adubação convencional no cultivo de milho doce, como na pesquisa de Kara e Atar (2013), que observaram comprimento máximo de espiga de $18,5 \mathrm{~cm}$, diâmetro de 4,65 cm e maior massa de 229,1 g.

\subsection{Avaliações físico-químicas}

Nas avaliações físico-químicas (Tabela 3), verificou-se diferença estatística entre os tratamentos para os parâmetros de pH, sólidos solúveis (SS), sólidos totais (ST) e cinzas. A acidez titulável em ácido málico não apresentou diferença significativa entre os tratamentos.

Mamede et al. (2014) analisaram parâmetros físico-químicos de cultivares de milho doce, com uso de adubação convencional, e observaram teor médio de sólidos solúveis de $15,49^{\circ} \mathrm{Brix}$. Comparando-se com esta pesquisa, apenas o tratamento 4 apresentou valor próximo a este, de $15^{\circ}$ Brix; os demais tratamentos apresentaram valores superiores ( $16^{\circ} \mathrm{Brix}$ e $17^{\circ} \mathrm{Brix}$ ), sendo os grãos do tratamento 2 com maior conteúdo de sólidos solúveis (17 ${ }^{\circ}$ Brix), o que pode ser uma referência a um maior teor de açúcares. É importante observar que as espigas do tratamento 2 apresentaram menor conteúdo de umidade, 0 que influencia no aumento do conteúdo de sólidos solúveis.

$\mathrm{O}$ aumento no número de aplicações de $\mathrm{N}$ para 6 e 8 (Tratamentos 3 e 4) acarretou um aumento no pH. Mamede et al. (2014) observou, nos grãos de milho doce, $\mathrm{pH}$ de 7,15 , que ficou próximo ao dos tratamentos $3(7,11)$ e $4(7,10)$. Já o valor médio da acidez titulável em ácido málico foi de $0,8 \%$, valor menor do que o encontrado nos tratamentos deste estudo, que variaram de $1,11 \%$ a $1,46 \%$.

Material mineral ou cinzas é o resíduo inorgânico que permanece após a queima da matéria orgânica, que é transformada em $\mathrm{CO}_{2}, \mathrm{H}_{2} \mathrm{O}$ e $\mathrm{NO}_{2}$. Os elementos minerais se apresentam nas cinzas sob a forma de óxidos, sulfatos, fosfatos, silicatos e cloretos, dependendo das condições de incineração e da composição dos alimentos (CECCHI, 2001). O tratamento 2 apresentou o maior 
conteúdo de cinzas $(2,01)$, diferindo estatisticamente dos demais.

Como era de se esperar, por apresentar maior resíduo mineral fixo, os grãos do tratamento 2 apresentaram o menor conteúdo de umidade $\left(69,08 \mathrm{~g} 100^{-1} \mathrm{~g}\right)$. De acordo com Cruz e Pereira Filho (2002), o milho deve ser colhido preferencialmente quando as espigas estiverem com 70 a $80 \%$ de umidade; assim, esse tratamento se mostrou, através da análise química, ligeiramente abaixo da faixa indicada para teor de umidade para colheita. Portanto, para esse tratamento, poderia ser indicada uma antecipação da colheita, o que seria vantajoso para o agricultor e para a indústria.

Luz et al. (2014) avaliaram características de híbridos de milho doce e verde, em função de intervalos de colheita, e observaram que a colheita mais tardia reduz a umidade dos grãos. Dessa forma, para o híbrido de milho verde SWC 02, a colheita deveria ser antecipada em função do conteúdo de umidade dos grãos, pois a conversão dos açúcares em amido altera a composição química, assim como alterou para o tratamento 2 do presente estudo.

A composição química dos grãos de milho é um fator importante na definição das propriedades de aceitação sensorial e qualidade industrial do produto (CANIATO et al., 2015).

\subsection{Análise sensorial e textura instrumental}

Os milhos correspondentes aos diferentes tratamentos apresentaram boa aceitação sensorial para os atributos avaliados (cor, sabor e textura). A maioria das médias manteve-se entre 7 e 8 , o que corresponde, na escala hedônica de notas utilizada pelos provadores, aos termos "gostei moderadamente" e "gostei muito", respectivamente. A maior média de 8,2 foi obtida pelo tratamento 3, para o atributo cor, enquanto a menor, de 7,3 , foi recebida pelo tratamento 4 , para o atributo sabor.

O teste de aceitação também demonstrou não haver influência dos tratamentos na avaliação dos atributos, na medida em que os mesmos não apresentaram grandes diferenças entre si, com médias entre 7 e 8 na escala hedônica de aceitação sensorial do milho doce.

A maior quantidade de açúcares presentes no milho doce pode ser o motivo dos bons índices de aceitação sensorial do mesmo. Em seu estudo com análise sensorial de híbridos de milho doce e verde, Camilo et al. (2015) observaram maior aceitação de híbridos de milho doce quando comparados com híbridos de milho verde. Além disso, verificaram também que a colheita, quando realizada entre 26 e 28 dias após o florescimento, proporciona produtos com melhores resultados sensoriais para textura, sabor e cor.

Segundo Chitarra e Chitarra (2005), o teor de umidade é diretamente proporcional à textura do produto, pois este é um dos fatores responsáveis pela turgidez e pela firmeza do tecido, ou seja, o turgor celular é perdido quando o tecido perde água ou morre.

De acordo com os resultados da textura instrumental, os milhos provenientes dos tratamentos 1 e 2 apresentaram textura mais firme, com valores de força de compressão de $157,07 \mathrm{~N}$ e $178,57 \mathrm{~N}$, respectivamente. No entanto, esta característica não influenciou na aceitação sensorial dos mesmos. A maior firmeza dos grãos oriundos dos tratamentos 1 e 2 pode ser relacionada com o menor conteúdo de umidade desses grãos, conforme observado anteriormente (Tabela 3).

Os grãos dos tratamentos 3 e 4 apresentaram textura mais macia, caracterizando-se por menores valores de força de compressão de 89,57 N e 102,33 N, respectivamente. Comparando-se a análise instrumental de textura e a análise sensorial de aceitação para o mesmo atributo, verificou-se que a diferença encontrada no teste instrumental entre os tratamentos 1 e 2 e os tratamentos 3 e 4 não foi perceptível durante o teste de aceitação sensorial, para o atributo textura.

Com relação ao atributo gosto doce, característico das variedades de milho doce, foi possível identificar, por meio do teste do ideal, em qual amostra a doçura foi considerada como ideal para este alimento, subjetivamente. A amostra do tratamento 2 foi a selecionada pela maioria dos provadores como a que apresentava a doçura ideal: 52,5\% marcaram o termo "ideal" para essa amostra (Figura 1). As amostras dos outros tratamentos apresentaram valores iguais, para o termo de doçura "ideal", de 32,5\%.

Vale ressaltar que tratamento 2 apresentou o maior conteúdo de sólidos solúveis (SS), com $17^{\circ}$ Brix (Tabela 3). De acordo com Chitarra e Chitarra (2005), o aumento da concentração de açúcares contribui para o incremento no valor dos sólidos solúveis; porém, o conteúdo de outras substâncias dissolvidas, como ácidos orgânicos, vitaminas, compostos fenólicos, entre outros, também pode influenciar o conteúdo de SS.

Para as amostras do tratamento 3, o termo com maior porcentagem de indicativo (37,5\%) foi "ligeiramente mais doce que o ideal". As variações para os apontamentos dos consumidores podem ser justificadas por se tratarem de provadores não treinados.

O tratamento 4 foi o único com marcações no termo "moderadamente menos doce que o ideal", sendo verificado que este tratamento foi o que apresentou menor valor de sólidos solúveis (15³rix) e maior conteúdo de umidade (Tabela 3).

Com relação à intenção de compra (Figura 2), as amostras do tratamento 2 apresentaram maiores porcentagens de intenção de compra positiva (65\%), referente aos termos "provavelmente compraria" (42,5\%) e "certamente compraria" (22,5\%). 


\section{IDEAL GOSTO DOCE}

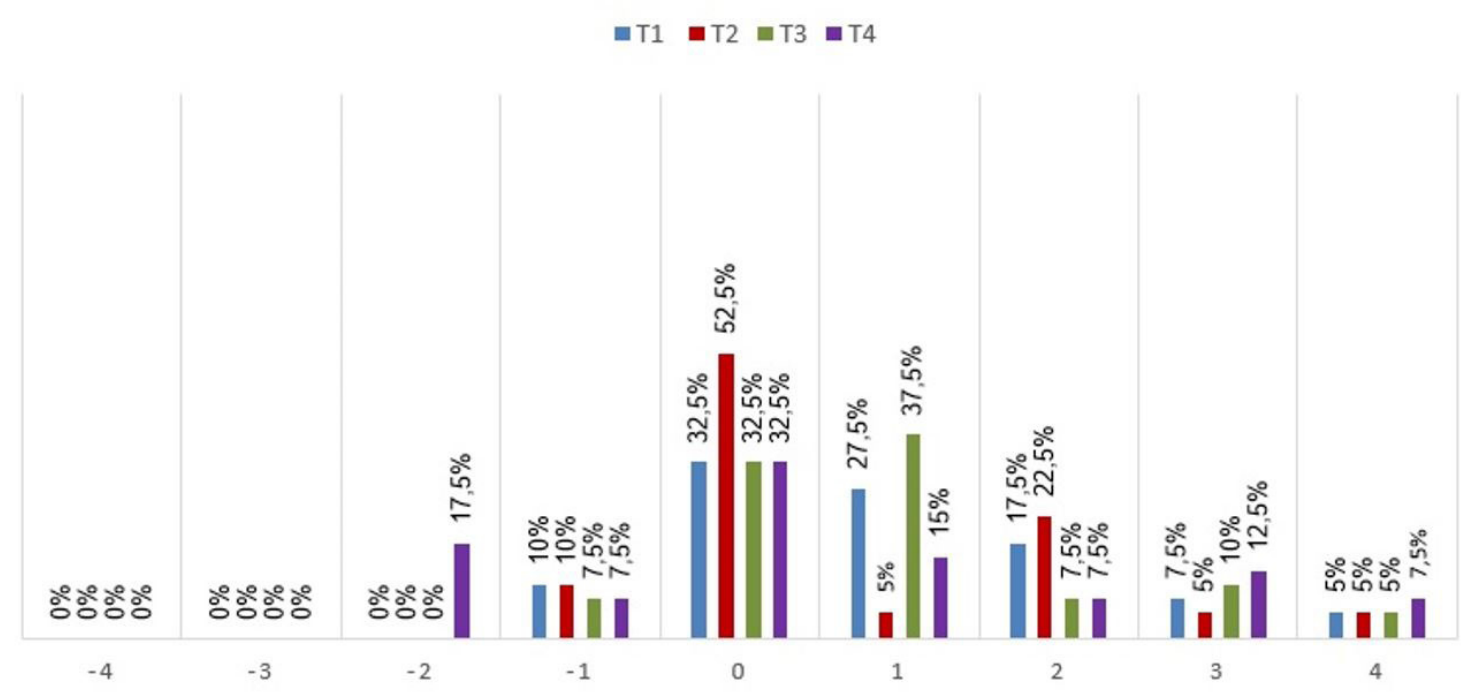

Figura 1. Teste ideal gosto doce em relação às amostras de milho doce. 4: extremamente menos doce que o ideal; 3: muito menos doce que o ideal; 2: moderadamente menos doce que o ideal; 1: ligeiramente menos doce que o ideal; 0: ideal; 1: ligeiramente mais doce que o ideal; 2: moderadamente mais doce que o ideal; 3: muito mais doce que o ideal; 4: extremamente mais doce que o ideal. T1: 2 aplicações; T2: 4 aplicações; T3: 6 aplicações e T4: 8 aplicações, ao longo do experimento de nitrato de amônio.

\section{INTENÇÃO DE COMPRA}

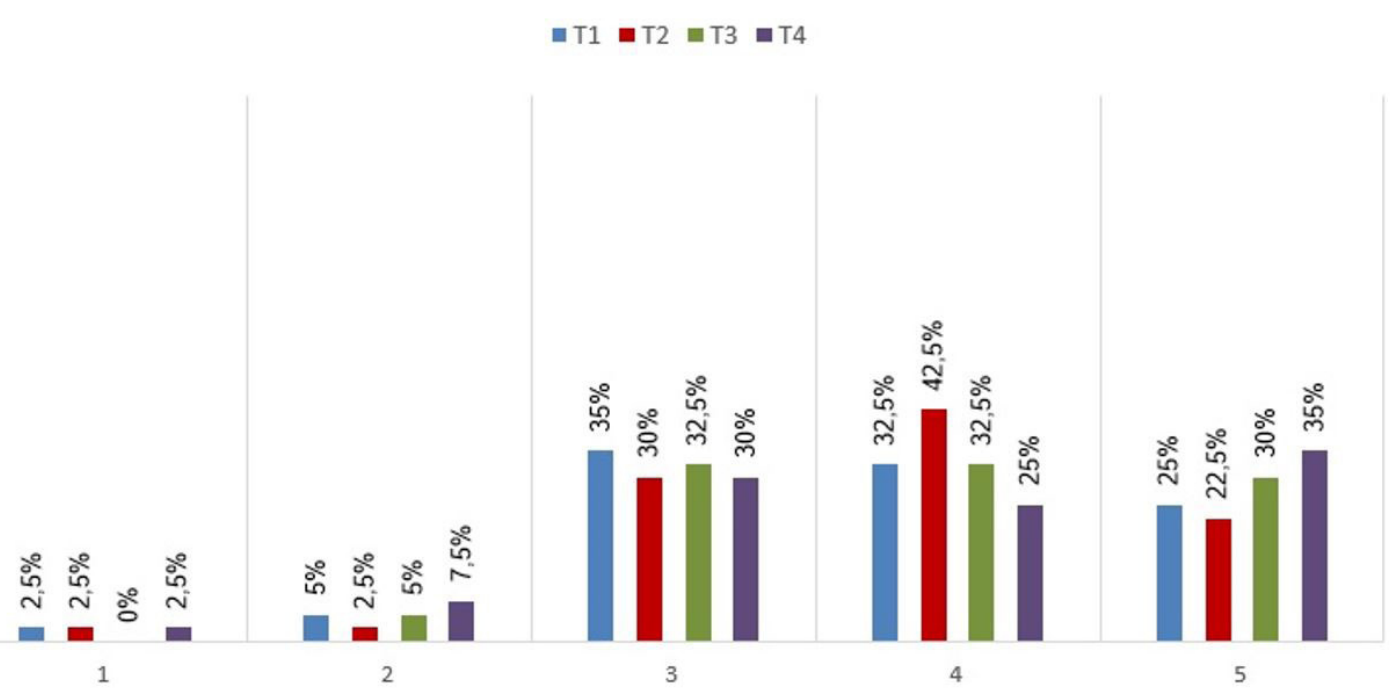

Figura 2. Intenção de compra em relação às amostras de milho doce. 1: certamente não compraria; 2: provavelmente não compraria; 3: tenho dúvidas se compraria; 4: provavelmente compraria; 5: certamente compraria.

O tratamento 4 obteve a maior porcentagem (35\%) para o termo "certamente compraria"; no entanto, foi o único a apresentar, mesmo que pequena (17,5\%), marcações para o termo "moderadamente menos doce que o ideal". Tal fato poderia ser um indicativo de que os consumidores estariam optando por comprar produtos com gosto doce menos acentuado, por questões de saudabilidade e também pelo fato de o consumidor estar mais habituado à aquisição e ao consumo do milho verde, o que também justifica índices expressivos para o termo "tenho dúvidas se compraria".

\section{Conclusões}

A fertirrigação na cultura do milho doce apresentou-se vantajosa, proporcionando a obtenção de espigas com maiores comprimentos, diâmetros e massas. 0 tratamento 2, 
Caracterização pós-colheita de milho doce submetido ao parcelamento de fertirrigação nitrogenada Perfeito, D. G. A. et al.

com parcelamento de nitrogênio em quatro aplicações, mostrou-se o mais favorável, pelo fato de a colheita poder ser antecipada em função da umidade dos grãos, além de apresentar bom rendimento em massa das espigas, boa aceitação sensorial, maior intenção de compra positiva e maior apontamento sensorial para a intensidade do gosto doce como ideal.

\section{Agradecimentos}

Ao Instituto Federal Goiano, Campus Urutaí, pelo auxílio financeiro e suporte na realização do projeto.

\section{Referências}

BARBIERI, V. H. B.; LUZ, J. M. Q.; BRITO, C. H.; DUARTE, J. M.; GOMES, L. S.; SANTANA, D. G. Produtividade e rendimento industrial de híbridos de milho doce em função de espaçamento e populações de plantas. Horticultura Brasileira, v. 23, n. 3, p. 826-830, 2005.

BHATT, P. S.; YAKADRI, M.; SIVALAKSHMI, Y. Influence of varying plant densities and nitrogen levels on yield attributes and yield of sweet corn. International Journal of Bio-Resource e Stress Management, v. 3, n. 3, p. 169-172, 2012.

CAMILO, J. S.; BARBERI, V. A. B.; RANGEL, R. M.; BONNAS, D. S.; LUZ, J. M. Q.; OLIVEIRA, R. C. Aceitação sensorial de híbridos de milho doce e híbridos de milho verde em intervalos de colheitas. Revista Ceres, v. 62, n. 1, p. 1-8, 2015. http:// dx.doi.org/10.1590/0034-737X201562010001.

CANIATO, F. F.; GALVAO, J. C. C.; FINGER, F. L.; RIBEIRO, R. A.; MIRANDA, G. V.; PUIATTI, M. Composição de açúcares solúveis totais, açúcares redutores e amidos nos grãos verdes de cultivares de milho na colheita. Revista Brasileira de Milho e Sorgo, v. 3, p. 38-44, 2015.

$\mathrm{CECCHI}, \mathrm{H}$. M. Fundamentos teóricos e práticos em análise de alimentos. 2. ed. Campinas: UNICAMP, 2001. 213 p.

CHITARRA, M. I. F.; CHITARRA, A. B. Pós-colheita de frutos e hortaliças: fisiologia e manuseio. 2. ed. Lavras: UFLA, 2005. $249 \mathrm{p}$.

CRUZ, C. A. Produtividade e rendimento industrial do milho doce irrigado em função de dose e parcelamento de nitrogênio. 2014. 25 f. Dissertação (Mestrado em Agronomia)-Faculdade de Ciências Agrárias e Veterinárias, Universidade Estadual de São Paulo, Jaboticabal, 2014.

CRUZ, J. C.; PEREIRA FILHO, I. A. Manejo e tratos culturais para o cultivo do milho verde. Sete Lagoas: Embrapa Milho e Sorgo, 2002. 9 p. Circular Técnica, 16.

FREITAS, Z. M. T. S.; LEMOS, M. A.; GAMAE, E. G.; TABOSA, J. N.; SANTOS, V. F. Parâmetros genéticos e fenotípicos de uma população de milho doce cristal. In: Congresso Nacional de Milho e Sorgo, 22., 1998, Recife. Anais... Recife: ABMS, 1998. CD-ROM.
INSTITUTO ADOLFO LUTZ - IAL. Métodos químicos e físicos para análise de alimentos. 4. ed. São Paulo: IAL, 2008. 1020 p.

KARA, B.; ATAR, B. Effects of mulch practices on fresh ear yield and yield components of sweet corn. Turkish Journal of Agriculture and Forestry, v. 37, n. 3, p. 281-287, 2013. http:// dx.doi.org/10.3906/tar-1206-48.

LUZ, J. M. Q.; CAMILO, J. S.; BARBIERI, V. H. B.; RANGEL, R. M.; OLIVEIRA, R. C. Produtividade de genótipos de milho doce e milho verde em função de intervalos de colheita. Horticultura Brasileira, v. 32, n. 2, p. 163-167, 2014.

MAMEDE, A. M. G. N.; CHITARRA, A. B.; FONSECA, M. J. O.; ANTONIO, G. S.; PEREIRA, I. A. F. Qualidade do milho doce minimamente processado conservado sob diferentes atmosferas. Engenharia na Agricultura, v. 22, n. 6, p. 520-534, 2014

MEILGAARD, M.; CIVILLE, G. V.; CARR, B. T. Sensory evaluation techniques. 3th ed. New York: CRC Press, 1999. 387 p.

MENDONÇA, F. C.; MEDEIROS, R. D.; BOTREL, T. A.; FRIZZONE, J. A. Adubação nitrogenada do milho em um sistema de irrigação por aspersão em linha. Scientia Agrícola, v. 56, n. 4, p. 10351044, 1999.

OLIVEIRA JUNIOR, L. F. G.; DELIZA, R.; BRESSAN-SMITH, R.; PEREIRA, M. G.; CHIQUIERE, T. B. Seleção de genótipos de milho mais promissores para o consumo in natura. Ciência e Tecnologia de Alimentos, v. 26, n. 1, p. 159-165, 2006.

PAES, M. C. D.; TEIXEIRA, F. F.; FARIA, D. G.; GUIMARAES, A. G.; BARBOSA, N. A. Avaliação de atributos de qualidade em híbridos experimentais de milho doce. In: Congresso Nacional de Milho e Sorgo, 28., 2010, Goiânia. Anais... Goiânia: ABMS, 2010. p. 3131-3135. CD-Rom.

SALOMÃO, L. C. Calibração de tanques evaporímetros de baixo custo sob diferentes diâmetros em ambiente protegido. 2012. 75 f. Tese (Doutorado em Agronomia)-Faculdade de Ciências Agronômicas, Universidade Estadual Paulista, Botucatu, 2012.

SOUZA, V. F.; COELHO, E. F.; PINTO, J. M.; NOGUEIRA, L. C.; COELHO, M. A.; ARAÚJO, A. R. Manejo da fertirrigação em fruteiras e hortaliças. In: SOUZA, V. F.; MAROUELLI, W. A.; COELHO, E. F.; PINTO, J. M.; COELHO FILHO, M. A. Irrigação e fertirrigação em fruteiras e hortaliças. Brasília: Embrapa Informação Tecnológica, 2011. p. 318-337.

TRANI, P. E.; TIVELLI, S. W.; CARRIJO, O. A. Fertirrigação em hortaliças. 2. ed. Campinas: IAC, 2011. 51 p. Boletim Técnico, 196.

XIAOLONG, S.; YUNFEI, L. Quality control of fresh sweet corn in controlled freezing-point storage. African Journal of Biotechnology, v. 10, n. 65, p. 14534-14542, 2011. http://dx. doi. org/10.5897/AJB10.1940.

ZUCARELI, C.; PANOFF, B.; PORTUGAL, G.; FONSECA, I. C. $B$. Doses e épocas de aplicação de nitrogênio em cobertura na qualidade fisiológica de sementes de milho doce. Revista Brasileira de Sementes, v. 34, n. 3, p. 480-487, 2012. http:// dx.doi.org/10.1590/S0101-31222012000300016. 